\title{
Strategic Approach in Social Media Marketing and a Study on Successful Facebook Cases
}

\author{
Filiz Bozkurt Bekoglu, PhD \\ Dogus University, Turkey \\ Cemre Onayl, MA \\ Goldsmith’s University of London
}

doi: 10.19044/esj.2016.v12n7p261 URL:http://dx.doi.org/10.19044/esj.2016.v12n7p261

\begin{abstract}
Development of Internet and social media has led to significant changes in marketing. Companies are now making serious efforts to integrate social media into their marketing strategies. In order to be successful in these efforts, marketing experts need to think strategically, integrate social media campaigns into their marketing plans and use the right tools in the right way. They should also evaluate the campaign performance and its effect on business performance. The aim of this study is to define the strategic approach adopted by the companies and to explore how companies structure and measure their campaigns. First of all, literature review was made and then twenty successful Facebook campaigns were selected and analyzed through content analysis within the scope of this study. The result of the analysis shows that companies used megaphone strategy (by informing consumers through pages, advertisements and videos) and magnet strategy (by creating an environment for interaction through applications, surveys and competitions), however they did not use monitor strategy (following customers interaction with one another). Regarding how the campaigns are structured, it is found that half of them aimed to give new information and $20 \%$ aware supported in offline platforms. The most preferred tool was the Facebook page, Facebook advertisements were more popular when compared to Facebook videos and the usage rate for surveys, competitions and applications were low. It is also found that like rate and participation rate were the two basic criteria companies used to measure the campaign performance however, as the data provided by the companies were limited, it was not possible to comment on the general strategic approach they adopted.
\end{abstract}

Keywords: Social media marketing, social media strategies, social media performance, return on investment 


\section{Introduction}

With the booming Internet, concepts such as digital media, social media and interactive media have emerged. Although Internet environment and social web are integrated, one feature distinguishes social media from the Internet: interaction. Social web is designed to bring users together, encourage them to share content and to build communities.

Parallel to the rapid technological improvements in the world today, Internet penetration and social media usage rates have increased dramatically. With 1.550 million monthly active users worldwide, Facebook is the most popular social media platform where online users engage with each other and with brands (Statista, 2016). Similarly, it is far ahead of other social media platforms in Turkey given that the number of Facebook users is around 40 million, which corresponds to $52.8 \%$ of total population in the country as of November 2015 (Internetworldstats, 2015).

eMarketer's study reveals that the amount of time spent on mobile devices such as smart phones and tablets, is predicted to surpass the amount of time dedicated to desktops/laptops. (eMarketer, 2015) Mobile devices facilitate easy, fast and instant communication among users by keeping them connected to the online world and thus encouraging interaction across time and space. In this respect, greater levels of interactivity, feedback, customization, clarity, and support are keys to social media performance of a company (Hill \& Moran, 2015).

Mangold \& Faulds (2009) mention that social media enables one person to communicate with many people about products and companies. Nevertheless, this conversation cannot be controlled directly by the company. Therefore, it is essential for the companies to learn how to shape this communication by using various tools. The most popular channels used by companies are microblogs (e.g. Twitter), social networks (e.g. Facebook) and socialized microsites, followed by video sharing and discussion forums (Ashley \& Tuten, 2015). On all these platforms, users follow and/or like brands and generate content by sharing their experiences and opinions. These online activities contribute to the company's shareholder value, especially after 'critical mass of followers is attained' (Paniagua \& Sapena, 2014). More than two million Facebook users in Turkey are fans of top 20 brands (Socialbakers, 2015). Therefore, companies should always take into consideration people's buzz, opinions and experiences while planning their marketing activities. Social media does not only offer a platform where brands engage in a social dialogue, it also enables brands to reach quantitative data about their customer segments, their needs and preferences. This information gives a crucial insight for companies that desire to understand who their real customers are. 


\section{Social Media Marketing}

Previously, companies could convey their advertising messages through traditional channels such as radio, television, newspapers, magazines and direct mail however it was impossible to target specific groups with individualized messages through these channels (Scott, 2015). Parallel to the developments in Internet and social media, the use of digital marketing has increased significantly and agencies offering consultancy in digital marketing have flourished. Also, new positions such as social media expert and community manager emerged. The responsibility of these people is to manage the presence of a brand or an initiative in the Internet environment.

Digital ad expenditures grew by $17.7 \%$ in 2014, and are expected to increase by another $15.5 \%$ as of 2015 . eMarketer reveals that digital media expenditures account for $28.2 \%$ of total advertisement expenditures, of 10.6\% was for mobile devices in 2014 (CMO Council, 2015). StrongView and Selligent's survey shows that, $56.3 \%$ of companies are expected to increase their spending on social media marketing, while $55.9 \%$ on online display advertising and 51.9\% on mobile marketing in January 2016 (www.marketingcharts.com, 2015).

According to a survey conducted among marketers, the most prominent benefits acquired from social media marketing are defined as; increased exposure, increased traffic, loyal fans, marketplace insight and the leads generated. Other benefits mentioned are, improved search rankings, growth in business partnership, thought leadership, improved sales and reduced marketing expenses. (Statista, 2016)

Until recently the only purpose of online marketing campaigns was to direct users to websites with a click. It then transformed to building sustainable relation with the consumers (Harris \& Rae, 2009). Social media brought highly important novelties to marketing and gave brands the opportunity to engage with existing and potential customers. One of the concepts highly associated with social media is word-of-mouth marketing, which is also known as viral, buzz or guerilla marketing. A study on social media marketing revealed that word-of-mouth effect increased the influence of messages and at the same time transformed them. (Kozinets et al, 2010).

Online marketing has recently boomed. The Marketing Manager of King of Shaves points out that, there is no other communication channel that can compete with Facebook, YouTube and similar channels given the high number of its visitors. Digital marketing is defined as the sum of achievements paid (banner, pop-up etc.), owned (brand's website, social media accounts) and earned (social media sites, customer engagement on other platforms and word-of-mouth effect). A brilliant social marketing case, Oldspice owes its success to the efficient use of spaces it owned and earned in social media (Datamonitor, 2010). 


\section{Strategic Approach in Social Media Marketing}

Strategic approach requires companies to define their marketing strategy in line with the corporate strategy. At this stage, customers, competitors and external factors as well as internal resources are taken into consideration. Then tactics are defined for the product, price, place and promotion. Return on Investment is an essential part of strategic management process as it gives the company the opportunity to measure the effects of the strategy and make an adjustment if necessary. Social media strategies are built by listening to and engaging with three types of personas: influencers, individuals and consumers. The engagement phase requires companies to define the motivations of these three personas and shape their strategies accordingly (Powell et al., 2011).

Although companies are aware of the fact that social media is an effective medium for marketing communications, they usually treat social media platforms such as YouTube, Facebook and Twitter as stand-alone elements instead of trying to integrate them into their marketing strategy (Hanna et al., 2011) and most of the time they do not have clear objectives that would give direction to their social media strategies (Charlesworth, 2015). Social media offers various tools to marketers and companies should decide how they will combine these tools depending on their target groups and expectations from the social media. Their social media strategy should also comply with their capabilities and they should define which success criteria to use.

Most of the sources in the related literature approach social media at a tactical level by defining tools in the digital environment and making recommendations on how these tools should be combined. Two experts working for two different digital advertising agencies (one of them working as the Director of Strategy and Business Development and the other one as the Director of Social Media.) were contacted to get their opinion on how strategy is defined in the digital marketing environment. Both of them used the term 'strategy' to refer to the social media activities they executed and what they mentioned was tactical (the tools they used and how they used them) rather than strategic (how they combined these tools and integrated social media in their marketing strategy). They said that when making a campaign proposal to their customers, they gave recommendations on which platforms and tools to use and how to use them and this represented their strategic approach. So expert views were parallel to the approach in the literature and most of the time social media marketing was taken at a tactical level.

Marketing communication in the online media is similar to traditional channels and has three aims: reminding, informing and convincing. In some sources, social media strategies are related to communication strategies as 
well as push-pull strategies and conversation is placed at the center (Neyck, 2004). Companies perform different roles in this conversation related to their position and they monitor, participate in or manipulate the conversation. In 'Social Media Bible,' by Safko (2010), a company’s social media strategy is resembled to a platform with four pillars: Communication, Cooperation, Education and Entertainment. These pillars are expected to be balanced to implement the social media strategy. Here, one of the most important points is that social media strategies need to be integrated to marketing strategies.

Two strategic approaches mentioned in the literature regarding social media are push and pull strategies and 3M model.

Push and Pull Strategies: Low cost electronic publishing lead to creation of huge information in many different channels. In this highly segregated and noisy environment, it is essential to integrate push and pull strategies to draw customers' attention to increase sales. Push strategies include special offers (discounts, coupons, sales) to push the product to the market. They are more suitable for lower value added brands (e.g. new software firms which increase their brand awareness by offering free trial versions). Pull strategies use advertisement and similar tools to create brand identity and pull consumers to the product. (Kambil, 1997).

3M Model: One of the most mentioned concepts in social media is dialogue or conversation, and social media strategies are designed to use this conversation to the company's advantage. A Hootsuite survey revealed that $60 \%$ of global organizations aim to plan actionable tactics from social data (Executive Leadership, 2015). The importance of listening to customers and getting information from them has long been an agenda, however social media has significantly changed the nature of interaction between the companies and consumers. Gallaugher \& Ransbotham (2010) conceptualized customer dialogue management with 3M Model: Megaphone, Magnet and Monitor. In this model, 'Megaphone' refers to company's interaction with customers, 'Magnet' to customers' interaction with companies and 'Monitor' to customers' interaction with one another. 'Megaphone' is very similar to push strategy whereas magnet to pull. The term 'monitor' which refers to listening to the conversation among customers is unique to social media and it added a new dimension to the well-known push-pull approach. In the offline platform, joining a conversation between customers or listening to them is only possible through mystery shoppers or market research. Starbucks is one of the most successful brands that integrated this model effectively to its customer relationship management. The company completely based its social media initiatives on this model.

With 'Megaphone' approach, Starbucks transmits comprehensive information to its target audience by using various social media tools. Although the company has branded social media accounts (e.g. Mystarbucks 
Idea), it maintains its visibility in third party websites through 'Megaphone' and communicates with consumers who are already on this platform. 'Magnet' approach enables Starbucks to pull customer dialogue to itself. Magnet initiatives take place either in their own websites or in third party websites. By using this tool, the company pulls all kinds of information (eg. opinions, videos, suggestions) from the customers. Starbucks puts most of its social media effort into encouraging dialogue among customers. The company actively monitors social media and selectively develops public or personal responses, which might be for; acknowledgement to a positive comment, correction of misinformation or apology. Dialogue among customers also spreads viral (Gallaugher \& Ransbotham, 2010).

\section{Measuring Campaign Performance in Social Media Marketing}

Measurement is an important part of strategic approach as it gives companies a chance to evaluate the performance and revise the strategy accordingly. Until recently, most of the social marketers believed that it was not possible or not necessary to measure social media. Besides, many marketers are not clear about how to do this (Powell et al., 2011). Recently, companies have started to use social media more frequently and the need to integrate social media into marketing communication strategies increased the importance of measurement. However, marketing experts are stuck between the pressure to take part in this new online communication and their expectations about the metrics that will justify the investment made to this platform. In order to make this measurement effective, marketers should work with the finance team to define the costs properly. They should also determine the potential returns in order to measure ROI effectively. (Powell et al., 2011).

Although there are various metrics to measure social media performance, it is not clear if these metrics have a relation with business value. Research made by Tata Consultacy services (2013) showed that, only half of the companies questioned, measured return on investment and one third of these mentioned that the results were negative. According to another survey by Duke University (2013), only 15\% of companies proved the impact of social media on their business. (Charlesworth, 2015). In web sources, there are also critiques regarding the use of ROI for the evaluation of social media performance. One of these critiques states that social media campaigns are successful because they are about people, not money. All buzz words- community, dialog, sharing- in social media are consumer oriented and social media is not about sales, market share or profit margins (Falls 2008).

There are conventional metrics, such as page view, time spent on the site, traffic and number of dialogue as well as domain specific metrics such 
as retweet number in Twitter, comments on blog entries, number of friends on a social platform (Chaney, 2009). Managers also keep an eye on informal conversation in the social media via Social Network Analysis to receive constant feedback on their strategies and change them accordingly (Eisenberg et al., 2015). Two models developed by agencies to measure online conversations about brands are, Digital Footprint Index (DFI) by Zocala Group and Social Influence Marketing (SIM) score by Razorfish. DFI combines information on four dimensions of online communication: volume (degree to which communication spreads), breadth (shared contents, comments), tone and echo. SIM score, on the other hand, combines online conversation on brands and consumer sensitivity. Both companies use data provided by platforms they monitor in their measurements (Fogel, 2010). Fisher (2009) mentioned some other metrics such as Collective Intellect, Cymfony, K.D. Paine and Associates, BuzzLogic. There are also tools as Alterian SM2, Radian6, Scoutlabs, Brandtology and Nielsen BuzzMetrics which enable companies to measure the basic social media activities (mentions in blog posts, micro-blog posts, social networks etc.) (Powell et al., 2011).

Interactive Advertisement Bureau (IAB, 2008) presents a clear frame where advertisers can measure their advertising activities on three basic social media platforms: social media sites, blogs and social media applications and defines metrics unique to each category. Social Media Sites; single visitor number, cost per single visitor, page view, visits, repeating visits, interaction rate, time spent, video upload, action, etc. Blogs; size of the conversation (number of websites, links and reach including content about the conversation related to the company), convenience of the blog (intensity of conversation, reliability of the author, novelty of content and its relevance to the topic, etc.). Social Media Applications; number of downloads, number of active users, audience profile, number of single user visits, growth, influence, number of download per user. These metrics are more complicated compared to traditional ones such as reach, frequency and click through rates and measure not only the amount of people who join the conversation, also how they join it. Therefore, in addition to monitoring a dialogue about a brand, it is possible to monitor the number of people who join the conversation and the motivation behind this act. Thus, rather than being a bulk of undefined conversation, social media is being transformed into a platform which may be joined, planned and purchased (Taylor, 2009). However, the usage of these metrics depends on the marketers views on effectiveness and the importance of measurement.

Fisher (2009) divides marketing experts into three groups based on their approach to ROI in social media. Deniers are totally against measuring the actions in social media, most likely due to their previous negative 
experiences, definers are not interested in the community side of the issue. They only look at click through rates. IAB metrics especially satisfy the needs of this group. They are highly open to new definitions and benchmarks. Dedicated ones believe that measurement of social media performance is not completely scientific and brings serious amount of workload. However, this group started to realize the importance of existing measurement systems - ie. web analytics, buzz monitoring and community monitoring- in following people's interaction with the brands.

Strategic approach requires companies to integrate social media into their marketing strategies. However, it is difficult to define the impact of social media performance on overall marketing performance. This prevents companies from measuring the Return on Investment accurately in social media. Oldspice's famous 'Smell Like a Man, Man’ campaign reveals how social media can be efficiently used to reach a wide range of target audience, to increase sales and to trace return of investment and time they devote to social media. Nevertheless, it is not possible to relate sales increase during the campaign period completely to social media. In this case, social media campaign was used along with a discount coupon, however sales increase was found to be higher when the discount coupons were used alone before the social media campaign started. This case is a good example showing that social media performance may not always increase business performance which is sales in this case- and coupon discounts may have a greater influence on sales than social media. (Datamonitor, 2010).

\section{Research Methodology}

In order to explore how companies structure and measure their social media campaigns, Facebook, which is the most popular social media platform, is chosen for this study. Facebook mainly aims to provide an online environment for friends, families and colleagues to communicate effectively, nevertheless it is also a highly effective medium that can also be used for marketing, corporate communications and public relations. It offers options such as like, share and comment which enable users to share the content they like with their social network. Facebook also aids companies to deliver information about their products and services through friend to friend communication, groups and applications (Scott, 2015). These functions trigger word-of-mouth communication and contribute to fast transmission of the messages. Yet, transmission capability of a message depends on its content, how appealing it is and what it offers. Although Facebook is the most popular advertisement platform in the social media, companies without sufficient experience in this field are not clear about how to benefit from this medium and how to evaluate the outcome.

The main purpose of this research is to identify how the campaigns 
are structured and measured in Facebook. Twenty cases from different sectors were selected from Facebook Marketing Solutions page through judgmental sampling. Content analysis was used to categorize the information in the campaign reports according to the criteria defined through the literature review and pre-evaluation of cases. Content analysis is a qualitative research method conducted to measure the independent variables in a text systematically, objectively and qualitatively (Adelaar, 2006). Then the information given for each criterion was coded and descriptive analysis was made to comment on the issues questioned.

The research is limited to the cases selected from Facebook Marketing Solutions page and to the information given by the companies studied. Data given in the reports were mainly limited to the campaign performance, therefore it was not possible to make a comment regarding the impact of campaign performance on business performance. Another limitation is the number of cases covered within the study.

\section{Research Findings}

The criterion defined to analyze the cases are: aim of the campaign, presence of offline support, Facebook tools used in the campaign ( advertisement, video, survey, competition, application) and measurement tools used to evaluate the campaign performance. The brands included in the study and the tools the companies used for the campaign are shown in Table 1.

In general, the companies used megaphone (by informing consumers through pages, advertisements and videos) and magnet strategies (by creating an environment for interaction through applications, surveys and competitions), whereas they did not use monitor strategy (following customers interaction with one another).

Although figures regarding the campaign performance were reported quantitatively in the cases, there was no systematic method used to report these results. There was also no satisfactory data regarding the impact of social media campaigns on business performance (such as sales, awareness and reputation). Therefore, it was not possible to make an objective comment on the campaign performance and its impact on business performance. However, the data enabled to explore how campaigns were structured and measured. Thus the usage rate for various tools and the measurement criterion used to evaluate campaign performance (participation, like) were analyzed and reported. The findings of the research are as follows 
Table 1: Facebook marketing cases selected for the research

\begin{tabular}{|c|c|c|c|}
\hline & Brand & Sector & Facebook tools used \\
\hline 1 & Budweiser & Beer & Page, application \\
\hline 2 & Samsung & Electronic & Video, survey, competition \\
\hline 3 & Marmite Bar & Food & Ad \\
\hline 4 & Nokia & Telecom. & Page, video \\
\hline 5 & Eastpak & Outdoor & Page, video \\
\hline 6 & Kia Motors & Automative & Page, video, survey \\
\hline 7 & Sony Pictures & Entertainment & Page, video \\
\hline 8 & Visit Britain & Tourism & Page \\
\hline 9 & CM Photography & Photography & Page, ad \\
\hline 10 & YO! Sushi & Restaurant & Page \\
\hline 11 & ZipZap Play & Web game & Page, ad \\
\hline 12 & PepsiCo & Soft drinks & Ad, survey \\
\hline 13 & M\&M & Confectionary & Page, application \\
\hline 14 & Nike & Sports wear & Page, ad \\
\hline 15 & Lacoste & Clothing & Ad \\
\hline 16 & Maybelline & Cosmetics & Page, competition \\
\hline 17 & Victory & Motorcycle & Page, ad \\
\hline 18 & Pedigree & Dog Food & Page, ad \\
\hline 19 & Clorox & Household & Page, ad, survey \\
\hline 20 & Hapa Spread & Food & Ad \\
\hline
\end{tabular}

Aim of the campaign: 55\% of the campaigns aimed to transmit new information (new product, new campaign) whereas the remaining $45 \%$ aimed to remind the brand.

Offline support: While 20\% of Facebook campaigns were supported in offline platforms such as television, press and mobile platforms, a high majority was run only on Facebook. Analysis of the campaign results reveals that Facebook campaigns have the potential to achieve high performance without any offline support.

Facebook tools used: The tools that may be used in a Facebook campaign are; pages, ads, videos, surveys, competitions and applications. The result of the analysis shows that $75 \%$ of companies that run Facebook campaigns, opened Facebook pages in addition to their websites. The remaining $25 \%$ preferred to use their websites during the campaign period and some of them directed the consumers to their websites by putting a link on the tool they used. $50 \%$ of the companies used Facebook advertisements while the rate of those who used videos was 25\%. The main difference between advertisements and videos is that, videos are more amateur compared to advertisements. The usage rate was $20 \%$ for surveys and $10 \%$ for competitions. The usage rate of Facebook applications, which offer a virtual experience to consumers and have a high impact on raising brand 
awareness, was also $10 \%$.

Measurement criteria used to evaluate campaign performance: The research shows that like rate and participation rate were the two basic criteria companies used to measure the campaign performance. Within this study, like rates (for pages, videos, ads) were measured for all the campaigns however, participation rates (for competitions, surveys, applications) were measured only for $70 \%$ of the campaigns, which means the remaining $30 \%$ did not use tools that required participation. Companies used various activities that the consumers could participate For instance, Budweiser offered online face painting, Samsung run a competition to raise awareness for its new tablet, and Nokia asked for consumers' views on its new ovi maps. In some cases, action was created through Facebook pages. For example, Marmite Bar distributed samples, Kia Motors offered a test drive, Yo Sushi offered a discount coupon and Pedigree dog food gave dog owners samples through their pages.

\section{Conclusion}

The development of Internet and social media has significantly changed the communication environment throughout the world. This new and highly effective medium offers new opportunities for marketing as well. Although companies are aware of these opportunities, they are not sure how they can integrate social media into their marketing plans. Thus their effort seems to be tactical rather than strategic. However, in today's highly competitive world, strategic thinking is the key to success in business world.

Lack of strategic approach is also observed in the literature related to social media marketing. However, in some sources, push and pull strategies are defined for social media. In one of them, social media strategy is related to 3M model for customer dialogue management, where megaphone (similar to push strategy) is used for company's interaction with customers, magnet (similar to pull strategy) for customers' interaction with companies and monitor for customers' interaction with one another. Regarding the measurement and return on investment issues, it is found that there is a wide range of tools. However, companies are not clear about which tools they should use and what benefit they will have from using them. On the other hand, there are some views which suggest that social media is about people, not money. According to this view, effort to evaluate social media performance with sales, market share and profit margins can be misleading about the real success of the campaign as the aim is to impress people, not to earn more money. So it seems essential to communicate the use and benefit of the metrics better.

There are various platforms companies can utilize while designing a campaign in social media. As Facebook seems to be the most popular 
platform that can be used for marketing, the research part of the study is based on Facebook campaigns. In order to explore how companies structure and measure their social media campaigns, twenty successful Facebook cases from various sectors were selected judgmentally from Facebook Marketing Solutions Page. These cases were analyzed to define the strategic approach companies adopted and to explore how these campaigns were structured and measured. In general, companies used megaphone (by informing consumers through pages, ads and videos) and magnet strategies (by creating an environment for interaction through applications, surveys and competitions), however they did not use monitor strategy (following customers interaction with one another).

Regarding how the campaigns are structured, it is found that half of the campaigns aimed to give new information and $20 \%$ of the campaigns were supported on offline platforms. Among various Facebook tools (pages, ads, videos, surveys, competitions and applications), Facebook page was the most preferred one. This is probably related to the easiness and low cost of opening a page. Facebook advertisements were preferred more when compared to Facebook videos, nevertheless the usage rate for these tools was lower than the pages. This may be related to the fact that Facebook advertisements require a special production and thus cost more. The usage rate for surveys and competitions was low and the reason behind this is predicted to be insufficient participation rate and the need to integrate these tools with a reward, lottery or coupon to get a good result. The usage rate for Facebook applications was also low and this is probably related to the difficulty of creating attractive viral applications and need to develop specific software. Regarding the measurement, it is found that like rate and participation rate were the two basic criteria companies used to measure the campaign performance.

In the campaign reports, the companies did not mention how they integrated their Facebook campaigns into their marketing plans. All companies measured the activity for the tools they used, however this data alone were not enough to evaluate the campaign performance. In some cases, sales increase during the campaign period was also reported, however these data were limited to only few cases. As a result, the information in the reports included more data on the tactical side of the campaigns. It is believed that the companies chose not to share the data regarding the campaign performance and business performance due to confidentiality. Thus in order to determine the strategic approach along with the evaluation of campaign performance and its impact on business performance, in-depth interviews may be held with the marketing managers of companies which use digital marketing intensively and with the managers of digital agencies which provide consultancy to companies on social media marketing. Future 
studies with larger samples based on Facebook and other social media platforms are believed to give more insight about strategic approach in social media marketing.

\section{References}

Adelaar, Thomas (2006), Click and Mortar Strategies Viewed From the Web: A Content Analysis of Features Illustrating Integration Between Retailers Online and Offline Presencell, Electronic Markets, Vol. 15, No. 3, s.1-30.

Ashley, C., \& Tuten, T. (2015). Creative Strategies In Social Media Marketing: An Exploratory Study of Branded Social Content and Consumer Engagement. Psychology \& Marketing, 32(1), 15-27.

Chaney, P., (2009). The Digital Handshake. JohnWiley\&Sons, Inc, New Jersey Charlesworth, A. (2015). An Introduction to Social Media Marketing. Routledge.

CMO Council, (2015). Facts and Stats. Retrieved 08.02.2016 https://www.cmocouncil.org/ facts-stats-categories.php?view=all\&category =marketing-spend

Datamonitor, (2010). Old Spice Case Study: Effectively Harnessing Social Media in Personal Care, Retrieved 07.02.2016. https://goodpackaged consumers.files.wordpress.com/2012/09/595 fds43514.pdf

Eisenberg, E. M., Johnson, Z., \& Pieterson, W. (2015). Leveraging Social Networks for Strategic Success. International Journal of Business Communication, 52(1), 143-154.

Emarketer, (2015). Average Time Spent per Adult User per Day with Digital Media, USA. Retrieved 23.02.2016, http://www.emarketer.com/Article/ Growth-ofTime-Spent-on-Mobile-Devices-Slows/1013072

Executive Leadership (2015). Marketing Trends for Social Media Managers, 30(3), 5 .

Fall , J. (2008), Perhaps Social Media Measurement Shouldn’t Matter, Social Media Explorer Retrieved 23.01.2016 https://www.socialmedia explorer.com/social-media-marketing/perhaps-social-media-measurement-shouldntmatter/

Fisher, T., (2009). ROI in social media: A look at the arguments. Database Marketing \& Customer Strategy Management, Vol. 16, 3, 189-195

Fogel, S. (2010). Issues in Measurement of Word of Mouth in Social Media Marketing. International Journal of Integrated Marketing Communications, 2(2).

Gallaugher, J., Ransbotham, S. (2010). Social Media and Customer Dialog Management at Starbucks, MIS Quarterly Executive, Vol 9, No 4

Hanna, R., Rohm, A., \& Crittenden, V. L. (2011). We're All Connected: The Power of the Social Media Ecosystem. Business Horizons, 54(3), 265-273.

Harris, L. \& Rae, I., (2009). Social Networks: The Future of Marketing for Small Business. Journal of Business Strategy, Vol . 30 No. 5, pp. 24-31.

Hill, R. P., \& Moran, N., (2011). Social Marketing Meets Interactive Media: Lessons for the Advertising Community. International Journal of Advertising, 30(5), 815-838.

IAB/Interactive Advertising Bureau, (2009). Social Media Ad Metrics Definitions. 
Retrieved 07.02.2016, http://www.iab.net/media/file/Social-Media-MetricsDefinitions-0509.pdf

Internetworldstats, (2015). Retrieved 07.02.2016. http://www.internetworld stats.com/ europa2.htm

Kambil, A. (1997). Doing Business in the Wired World, Computer, 30 (5), 56-61.

Kozinets, R. V., De Valck, K., Wojnicki, A. C., \& Wilner, S. J. (2010). Networked Narratives: Understanding word-of-mouth Marketing in Online Communities. Journal of Marketing, 74(2), 71-89.

Mangold, W. G., \& Faulds, D. J. (2009). Social Media: The New Hybrid Element of the Promotion Mix. Business Horizons, 52(4), 357-365.

Nyeck, S. (2004). Luxury Brands Online and Offline: The Case of French Brands. European Retail Digest, Spring, 41, p.1-5

Paniagua, J., \& Sapena, J. (2014). Business Performance and Social Media: Love or Hate?. Business Horizons, 57(6), 719-728.

Powell, G.R., Groves, S.W., \& Dimos, J. (2011). ROI of Social Media: How to Improve the Return on Your Social Marketing Investment. John Wiley \& Sons.

Safko, L. (2010). The Social Media Bible: Tactics, Tools, and Strategies for Business Success. John Wiley \& Sons.

Scott, D. M. (2009). The New Rules of Marketing and PR: How to Use Social Media, Blogs, News Releases, Online Video, and Viral Marketing to Reach Buyers Directly. John Wiley \& Sons.

Socialbakers, (2015). December 2015 Social Marketing Report Turkey, Retrieved 08.02.2016, regional/turkey/2015/december/ http://www.socialbakers.com/resources/reports/

Statista, (2016). Global Social Networks Ranked by Number of Users, Retrieved 08.02.2016, http://www.statista.com/statistics/272014/global-social-networksranked-by-number-of-users/

Statista, (2016), What are the Benefits of Using Social Media for Marketing Purposes?, Retrieved 08.02.2016, http://www.statista.com/statistics/ 188447/influence-of-global-social-media-marketing-usage-on-businesses/

Taylor , C. ( 2009 ). Will the IAB’s Social Media Metrics Definitions Help Crack the Engagement Code?, Retrieved 02.01.2016, http://www. mediapost.com/publications/article/105556/will-the-iabs-social-media-metricsdefinitions-he.html www.marketingcharts.com, (2016). Marketing Budget Plans by Channel, Retrieved 08.02.2016, http://www.marketingcharts.com/online/2016-marketing-budget-trendsby-channel-64987/ 